\title{
Evaluation of Antibiotic Prescription in Medical Emergencies of the University Hospital Centre of Cocody-Abidjan
}

\author{
Balayssac Eric ${ }^{1,2 *}$, Koukougnon Serges ${ }^{2}$ \\ ${ }^{1}$ Clinical Pharmacology Service, University Teaching Hospital of Cocody, Abidjan, Ivory Coast \\ ${ }^{2}$ Department of Biochemistry, Physiology and Pharmacology, Training and Research Unit of the Medical Sciences of Abidjan, \\ Felix Houphouet Boigny University, Abidjan, Ivory Coast \\ Email: *ebalayssac@yahoo.fr
}

How to cite this paper: Eric, B. and Serges, K. (2019) Evaluation of Antibiotic Prescription in Medical Emergencies of the University Hospital Centre of Cocody-Abidjan. Pharmacology \& Pharmacy, 10, 507-518. https://doi.org/10.4236/pp.2019.1012042

Received: November 19, 2019

Accepted: November 30, 2019

Published: December 3, 2019

Copyright $\odot 2019$ by author(s) and Scientific Research Publishing Inc. This work is licensed under the Creative Commons Attribution International License (CC BY 4.0).

http://creativecommons.org/licenses/by/4.0/ c) (i) Open Access

\begin{abstract}
Objective: To evaluate the prescription of antibiotics in patients admitted, in December 2017, to the medical emergencies of the University Hospital Center (UHC) of Cocody. Methodology: A retrospective descriptive and analytical study of 187 patient files registered from December 1, 2017 to December 31, 2017 at the Cocody UHC's medical emergencies. All patients aged 16 and over, regardless of sex, nationality and place of residence, having consulted at the Cocody UHC Medical Emergencies and having received antibiotics locally or generally during the study period were included. Patients on antibiotics before admission to medical emergencies or admitted to medical emergencies but not treated with antibiotics or died in medical emergencies before receiving antibiotic therapy were not included in our study. Results: In one month, 265 antibiotic prescription lines were recorded in 187 patients divided into 113 men (60.42\%) and 74 women (39.57\%) with a sex ratio of 1.52 and an average age of 47.5 years. $58.62 \%$ (187/319) of patients had received antibiotic therapy for lung (32.23\%), neurological (21.49\%) and parasitological (13.22\%) affections. Beta-alactamines were the most prescribed molecules (70.57\%), mainly in monotherapy and intravenously. Antibiotic therapy was unjustified (66.41\%) with a non-compliant dosage $(29.43 \%)$. The evolution of patients on antibiotics was favourable (50.80\%) with however a death in $15.51 \%$ of cases. Conclusion: Antibiotic therapy in medical emergency at Cocody University Hospital was based on probabilistic reasoning. This implies that the emergency physician must have a good knowledge of the rules of antibiotics use and that he applies them.
\end{abstract}

\section{Keywords}

Prescriptions, Antibiotics, Hospital, Medical Emergencies 


\section{Introduction}

The discovery of antibiotics has been a major therapeutic advance of the twentieth century because it has allowed providing an adequate response to infectious diseases of bacterial origin [1]. From that time on, antibiotics developed exponentially, to such an extent that by the 1960s, three-quarters of antibiotic families were already represented [2]. The therapeutic success of antibiotics has contributed to their high consumption in the world, thus promoting the emergence of resistant bacterial strains and becoming a real public health problem [3] [4] [5]. Indeed, in Europe, antibiotic resistance results in 25,000 deaths per year and costs about 1.5 billion euros per year [6] [7].

In Côte d'Ivoire, a West African country, the cost of antibiotic resistance remains difficult to estimate, although antibiotics account for $25 \%$ of drug prescriptions. Apart from the importance of antibiotic prescriptions, which are established in certain part by paramedical personnel (66.53\% according to a study conducted in 6 peripheral health structure in Abidjan), antibiotics are often obtained, by self-medication, in private pharmacies or on streets [8] [9] [10]. These different types of antibiotic consumption have contributed to bacterial resistance. Indeed, several studies in Côte d'Ivoire have shown that antibiotics are abused or inadequately used in $5 \%$ to $78 \%$ of cases [8] [9] [10]. Other studies have highlighted, especially in 2008, the presence of Enterobacteriaceae secreting broad-spectrum beta-lactamases (ESBL), in 2012, the presence of multidrug-resistant bacteria (BMR) in the intensive care unit of the University Hospital Center (UHC) of Yopougon (a municipality of Abidjan) and in 2013, the presence of carbapenem-resistant Pseudomonas aeruginosa. In addition, a survey [8] estimated in 2003 the prevalence of antibiotic therapy at $43 \%$ in emergency medical services of three UHC in Abidjan (49\% in Treichville UHC, 44\% in Cocody UHC and 36\% in Yopougon UHC). In these services, misuse or inappropriate use of antibiotics would be linked to frequent prescription of antibiotics due to the high prevalence of community infectious diseases. Furthermore, the prescription of antibiotics is often empirical because it is established before the results of the bacteriological tests.

In this context, we focused on antibiotics prescriptions in medical emergencies to promote rational use of antibiotics and reduce bacterial resistance in Côte d'Ivoire. The second reason was the lack of national antibiotic prescribing standards.

Our general objective was to evaluate the prescription of antibiotics in patients admitted, in December 2017, to medical emergency department of Cocody UHC. The specific objectives were to estimate general frequency of antibiotic prescription, describe epidemiological characteristics of patients, specify the main indications and antibiotics molecules and verify the conformity and the relevance of antibiotherapy.

\section{Material}

A descriptive and analytical retrospective study was conducted in the Medical 
Emergency Department of Cocody University Hospital Centre (UHC). The said service consists of a sorting room with 4 beds and 8 hospitalization rooms with 41 beds (for a total capacity of 45 beds). It is integrated into the so-called grouped Emergency Department which includes Medical, Surgical, Gynaecological and Pediatric Emergencies. Thus, our study concerned 187 patient files out of 319 files archived over a one-month period (from December 1, 2017 to December 31, 2017). These files were selected on the basis of the criteria listed below.

\subsection{Study Population}

\subsubsection{Inclusion Criteria}

Included in the study were all patient files from 16 years of age and older, regardless of sex, nationality and place of residence, having consulted at Medical Emergencies of Cocody UHC and having received antibiotics locally and/or generally during the study period.

\subsubsection{Criteria for Non-Inclusion}

In contrast, were not included in our work, all patient files on antibiotics prior to their admission to medical emergencies or patients admitted to medical emergencies but not treated with antibiotics or patients who died before receiving antibiotic therapy or patients' files not available.

\subsection{Conduct of the Study}

As a first step, we developed, in the Clinical Pharmacology department of the Cocody UHC, a standardized survey form based on data from literature. Clinical Pharmacology Department is located in the group emergency room and has a triple mission of care, training and research. Its main purpose is to promote rational use of drug and improve the quality of care.

In a second step, we have, from Admissions Registry in medical emergency department, conducted a census of all patient records in our study period. This census allowed us to select 187 patient files, about 10 of which were used to test our survey form. This form included information on epidemiological data (age, sex, occupation), clinical data (reasons for consultation and/or hospitalization, history, selected diagnoses), paraclinical data (results of haematological, microbiological and radiological examinations), medicinal data (family and name of antibiotics prescribed, indications, dosage, route and duration of administration, 1st or 2nd line antibiotic therapy, monotherapy or combinations of antibiotics) and evolving data (improvement, persistence, aggravation or death).

In a third step, we evaluated the prescription of antibiotics using a reference book of the French-speaking society of infectious pathology [7] [11]. Thus, in absence of local antibiotic therapy guidelines and infectious disease physicians at Cocody UHC, we considered antibiotic therapy relevant when it was justified from an infectious point of view. Similarly, antibiotic therapy was considered compliant when the prescribed dosage, duration and route of adminis- 
tration of the antibiotics were in accordance with the recommendations of the said book.

\subsection{Statistical Analysis}

EPI INFO 2007 software version 7.1.3.3 was used for data entry, coding and statistical exploitation. The Pearson chi-square statistical test was used (significance threshold $\mathrm{p}<0.05)$ to compare qualitative variables.

\subsection{Ethical Considerations}

We had the oral authorization of the Chief of Emergency Services group before starting our study. Furthermore, the confidentiality of the data collected was guaranteed, as was the anonymity of the patients.

\section{Results}

\subsection{Socio-Demographic Data}

Over a one-month period, 265 lines of antibiotic prescriptions were identified in 187 patients who were divided into 113 men (60.42\%) and 74 women (39.57\%) with a sex ratio of 1.52 (Table 1 ). The difference between men and women treated with antibiotics was not significant $\left(\mathrm{Chi}^{2}=2.54\right.$; $\left.\mathrm{ddl}=1, \mathrm{p}=0.11\right)$. The average age was 47.5 years ( $46.31 \pm 17.56$ for men and $47.17 \pm 18.06$ for women) with extremes ranging from 16 to 87 years. There was no significant difference between men and women by age (Student $\mathrm{T}$ test, $\mathrm{p}=0.74$ ). Patients worked mainly in the informal sector (87/187). Furthermore, the frequency of prescription of antibiotics was estimated at $58.62 \%(187 / 319)$, or $62.43 \%(113 / 181)$ in men and 53.62\% (74/138) in women (Table 1$)$.

\subsection{Clinical and Paraclinical Data}

Our patients were hypertensive ( $\mathrm{n}=46 ; 34.84 \%)$, HIV-infected $(\mathrm{n}=22 ; 16.66 \%)$ and diabetics $(\mathrm{n}=20 ; 15.15 \%)$ (Table 1$)$. No history of drug allergy was reported. The reasons for admission were dominated by fever $(\mathrm{n}=27 ; 14.44 \%)$ and consciousness disorders $(\mathrm{n}=23 ; 12.30 \%)$ as shown in Table 2. Lung infections $(\mathrm{n}=39 ; 32.23 \%)$ and neurological disorders $(\mathrm{n}=26 ; 21.49 \%)$ were the main reasons for prescribing antibiotics followed by parasitic $(\mathrm{n}=16 ; 13.22 \%)$, digestive $(n=13 ; 10.74 \%)$ and sepsis $(n=10 ; 8.26 \%)$ disorders (Table 3$)$.

$85.56 \%(160 / 187)$ of patients had received a Blood Formula Count (BFC) before antibiotic therapy. This test had revealed hyperleukocytosis with neutrophils $(\mathrm{n}=70 ; 43.75 \%)$ or neutropenia $(\mathrm{n}=12 ; 7.50 \%)$. The second test, C-Reactive Protein (CRP), was positive in 97.70\% (85/87) of cases. However, apart from Widal-Félix test $(\mathrm{n}=2 ; 1.06 \%)$, no bacteriological examination has been prescribed. Similarly, no procalcitonin assays had been requested. In total, antibiotics were prescribed on paraclinical arguments $(n=80 ; 42.78 \%)$, clinical arguments $(n=71 ; 37.97 \%)$ or clinical and paraclinical arguments $(n=36$; $19.25 \%)$. 
Table 1. Characteristics of patients treated with antibiotics.

\begin{tabular}{|c|c|c|}
\hline Parameters & Number & Percentages (\%) \\
\hline Patient without antibiotics & 132 & 41.38 \\
\hline Patients on antibiotics & 187 & 58.62 \\
\hline \multicolumn{3}{|l|}{ Gender } \\
\hline Men & 113 & \multirow{2}{*}{$\begin{array}{l}62.43 \\
53.62\end{array}$} \\
\hline Women & 74 & \\
\hline Mean age (year) & $47.50[16-87]$ & \\
\hline Mean age Men (year) & $46.31 \pm 17.56$ & \\
\hline Mean age Women (year) & $47.17 \pm 18.06$ & \\
\hline \multicolumn{3}{|l|}{ Professions $(n=187)$} \\
\hline Informal sector & 87 & 46.52 \\
\hline Private sector & 23 & 12.30 \\
\hline Unemployed & 17 & 9.09 \\
\hline Student & 15 & 8.02 \\
\hline Retreat & 14 & 7.49 \\
\hline Pupil & 11 & 5.88 \\
\hline Agricultural sector & 8 & 4.28 \\
\hline Public service & 7 & 3.74 \\
\hline Not specified & 3 & 1.60 \\
\hline Other (Pastor, Sportsman) & 2 & 1.07 \\
\hline \multicolumn{3}{|l|}{ Past history $(\mathrm{n}=132)$} \\
\hline Hypertension & 46 & 3.84 \\
\hline HIV infection & 22 & $1 ., 66$ \\
\hline Diabetes & 20 & 1.15 \\
\hline Epigastric pain & 11 & 8.33 \\
\hline Sickle cell & 8 & 6.06 \\
\hline Brain stroke & 7 & 5.30 \\
\hline Pulmonary tuberculosis & 6 & 4.54 \\
\hline Prostatectomy & 5 & 3.78 \\
\hline Chronic renal failure & 3 & 2.27 \\
\hline Hepatic cirrhosis & 2 & 1.51 \\
\hline Appendectomy & 2 & 1.51 \\
\hline
\end{tabular}

Table 2. Reasons for consulting.

\begin{tabular}{ccc}
\hline Reasons & Number & Percentage (\%) \\
\hline Fever & 27 & $14.44 \%$ \\
Disorders of consciousness & 23 & $12.30 \%$ \\
Alteration of general condition & 19 & $10.16 \%$ \\
Motor deficiency of hemibody & 14 & $7.49 \%$ \\
Dyspnea & 13 & $6.95 \%$ \\
Clinical anemia & 12 & $6.42 \%$ \\
Convulsions & 11 & $5.88 \%$ \\
Headaches & 9 & $4.81 \%$ \\
\hline
\end{tabular}




\section{Continued}

\begin{tabular}{ccc} 
Coughing & 9 & $4.81 \%$ \\
Hematemesis & 8 & $4.28 \%$ \\
Unrest & 7 & $3.74 \%$ \\
High blood pressure attack & 7 & $3.74 \%$ \\
Abdominal pain & 6 & $3.21 \%$ \\
Epigastralgia & 6 & $3.21 \%$ \\
Chest pain & 5 & $2.67 \%$ \\
Vomiting & 4 & $2.14 \%$ \\
Hematuria & 4 & $2.14 \%$ \\
Epistaxis & 3 & $1.60 \%$ \\
Total & 187 & $100.00 \%$ \\
\hline
\end{tabular}

Table 3. Antibiotic therapy according to indications.

\begin{tabular}{|c|c|c|c|c|c|c|c|c|}
\hline $\begin{array}{l}\text { Antibiotics } \\
\text { Indications }\end{array}$ & $\begin{array}{l}\text { Amoxicilin + } \\
\text { Clavulanic } \\
\text { Acid }\end{array}$ & Ceftriaxone & Cotrimoxazole & Gentamycin & Metronidazole & RHZE & Ofloxacin & $\begin{array}{l}\text { Fusidic } \\
\text { Acid }\end{array}$ \\
\hline Hepatic abscess & $1(0.88 \%)$ & $1(1.35 \%)$ & & & $1(5.26 \%)$ & & & \\
\hline Cutaneous allergy & $1(0.88 \%)$ & & & & & & & \\
\hline Decompensated anemia & $2(1.77 \%)$ & $1(1.35 \%)$ & & & & & & \\
\hline Uncompensated anemia & $4(3.54 \%)$ & $1(1.35 \%)$ & & & & & & \\
\hline Hemorrhagic stroke & $13(11.50 \%)$ & $13(17.57 \%)$ & $5(18.52 \%)$ & $5(25.00 \%)$ & & & & \\
\hline Ischemic stroke & $6(5.31 \%)$ & $5(6.76 \%)$ & & $13(65.00 \%)$ & & & & \\
\hline Acute bronchitis & $8(7.08 \%)$ & $3(4.05 \%)$ & & & & & & \\
\hline Keto-acidosic coma & $2(1.77 \%)$ & $1(1.35 \%)$ & & & & & & \\
\hline Convulsive coma & $4(3.54 \%)$ & $4(5.41 \%)$ & $2(7.41 \%)$ & $2(10.00 \%)$ & & & & \\
\hline Acute diarrhea & $3(2.35 \%)$ & $3(4.05 \%)$ & $2(7.41 \%)$ & & $3(15.79 \%)$ & & $3(60 \%)$ & \\
\hline Infectious endocarditis & $1(0.88 \%)$ & $1(1.35 \%)$ & & & & & & \\
\hline Furunculosis & $1(0.88 \%)$ & & & & & & & $1(100 \%)$ \\
\hline Febrile gastroenteritis & $6(5.31 \%)$ & $6(8.11 \%)$ & $3(11.11 \%)$ & & $9(43.37 \%)$ & & $2(40 \%)$ & \\
\hline hydropneumothorax & $2(1.77 \%)$ & & & & & & & \\
\hline Chronic renal failure & $3(2.35 \%)$ & $3(4.05 \%)$ & & & $3(15.79 \%)$ & & & \\
\hline Lumbosciatica & $2(1,77 \%)$ & $1(1.35 \%)$ & & & & & & \\
\hline $\begin{array}{l}\text { Febrile } \\
\text { meningoencephalitis }\end{array}$ & $1(0.88 \%)$ & $1(1.35 \%)$ & $1(3.70 \%)$ & & & & & \\
\hline Miliary tuberculous & $1(0.88 \%)$ & $1(1.35 \%)$ & $1(3.70 \%)$ & & & $1(16.67 \%)$ & & \\
\hline Severe malaria & $6(5.31 \%)$ & $5(6.76 \%)$ & $3(11.11 \%)$ & & $3(15.79 \%)$ & & & \\
\hline Simple malaria & $4(3,54 \%)$ & $1(1,35 \%)$ & & & & & & \\
\hline Acute pneumopathy & $25(22.12 \%)$ & $12(16.22 \%)$ & $5(18.52 \%)$ & & & & & \\
\hline Hypertensive crisis & $2(1.77 \%)$ & $1(1.35 \%)$ & & & & & & \\
\hline Severe Sepsis & $8(7.08 \%)$ & $8(10.81 \%)$ & & & & & & \\
\hline Sepsis with skin entryway & $2(1.77 \%)$ & $2(2.70 \%)$ & & & & & & \\
\hline Pulmonary tuberculosis & $5(4.42 \%)$ & & $5(18.52 \%)$ & & & $5(83.33 \%)$ & & \\
\hline $\begin{array}{l}\text { Total } \\
\text { (Prescriptions lines) }\end{array}$ & 113 & 74 & 27 & 20 & 19 & 6 & 5 & 1 \\
\hline
\end{tabular}




\subsection{Therapeutic Data}

$70.57 \%(187 / 265)$ of the antibiotics prescribed belonged to the beta-lactam family (Table 4). Fixed association amoxicillin + clavulanic acid ( $n=113 ; 42.64 \%)$ and ceftriaxone $(\mathrm{n}=74 ; 27.92 \%)$ were the most prescribed molecules out of a total of 265 prescription lines reported (Table 5). These molecules were prescribed mainly in acute pneumopathies $(22.12 \%$ for amoxicillin + clavulanic acid and $16.22 \%$ for ceftriaxone), haemorrhagic strokes (11.50\% for amoxicillin + clavulanic acid and $\mathbf{1 7 . 5 7 \%}$ for ceftriaxone) and severe sepsis (7.08\% for amoxicillin + clavulanic acid and $10.81 \%$ for ceftriaxone) as shown in Table 3 . In addition, antibiotic combinations, representing 66 prescription lines (24.90\%), were dominated by the dual association ceftriaxone + metronidazole and ceftriaxone + gentamycin (Table 5). The intravenous route was predominant $(224 / 265)$ followed by the oral route $(21 / 265)$ and the local route $(1 / 265)$ with an average treatment duration of $3 \pm 1$ days. Antibiotic therapy was considered irrelevant in $66.41 \%$ of the prescription lines but compliant by route of administration and dosage in $93.96 \%(249 / 265)$ and $70.57 \%(187 / 265)$ of the prescription lines respectively. The course of 187 patients treated with antibiotics was marked by improved health status $(\mathrm{n}=95 ; 50.80 \%)$, persistence of disorders $(\mathrm{n}=48$; $25.67 \%)$, worsening pathology $(n=15 ; 8.02 \%)$ and death $(n=29 ; 15.51 \%)$.

Table 4. Antibiotic's families and molecules prescribed.

\begin{tabular}{|c|c|c|}
\hline Antibiotics & Number (Prescription lines) & Percentages (\%) \\
\hline & \multicolumn{2}{|c|}{ Bêta-lactam } \\
\hline Amoxicillin + clavulanic acid & 113 & $42.64 \%$ \\
\hline \multirow[t]{2}{*}{ Ceftriaxone } & 74 & $27.92 \%$ \\
\hline & \multicolumn{2}{|c|}{ Sulfamides } \\
\hline \multirow[t]{2}{*}{ Trimethoprim + sulfamethoxazole } & 27 & $10.19 \%$ \\
\hline & \multicolumn{2}{|c|}{ Aminosides } \\
\hline \multirow[t]{2}{*}{ Gentamycin } & 20 & $7.55 \%$ \\
\hline & \multicolumn{2}{|c|}{ Imidazoles } \\
\hline \multirow[t]{2}{*}{ Metronidazole } & 19 & $7.17 \%$ \\
\hline & \multicolumn{2}{|c|}{ Anti-tuberculosis } \\
\hline \multirow[t]{2}{*}{ RHZE $^{*}$} & 6 & $2.26 \%$ \\
\hline & \multicolumn{2}{|c|}{ Fluoroquinolones } \\
\hline \multirow[t]{2}{*}{ Ofloxacin } & 5 & $1.89 \%$ \\
\hline & \multicolumn{2}{|c|}{ Other } \\
\hline Fusidic acid & 1 & $0.38 \%$ \\
\hline Total & 265 & $100.00 \%$ \\
\hline
\end{tabular}

${ }^{*}$ RHZE: Rifampicin-Isoniazide-Pyrazinamide-Ethambutol. 
Table 5. Prescribed antibiotic combinations.

\begin{tabular}{|c|c|c|}
\hline Associations & Number (Prescription lines) & Percentages \\
\hline Ceftriaxone + metronidazole & 12 & $18.18 \%$ \\
\hline Ceftriaxone + gentamycin & 9 & $13.64 \%$ \\
\hline Amoxicillin + clavulanic acid + metronidazole & 8 & $12.12 \%$ \\
\hline Amoxicillin + clavulanic acid + trimethoprim + sulfamethoxazole & 7 & $10.61 \%$ \\
\hline Amoxicillin + clavulanic acid + ceftriaxone & 6 & $9.09 \%$ \\
\hline Ceftriaxone + RHZE & 5 & $7.58 \%$ \\
\hline Amoxicillin + clavulanic acid + ceftriaxone + metronidazole & 5 & $7.58 \%$ \\
\hline Amoxicillin + clavulanic acid + trimethoprim + sulfamethoxazole + RHZE & 4 & $6.06 \%$ \\
\hline Ceftriaxone $+\underline{\text { trimethoprim }+ \text { sulfamethoxazole }}$ & 3 & $4.55 \%$ \\
\hline Ceftriaxone + gentamycin + metronidazole & 3 & $4.55 \%$ \\
\hline Amoxicilline + clavulanic acid + metronidazole + ofloxacin & 2 & $3.03 \%$ \\
\hline Amoxicillin + clavulanic acid + gentamycin & 1 & $1.52 \%$ \\
\hline Ceftriaxone + trimethoprim + sulfamethoxazole + metronidazole & 1 & $1.52 \%$ \\
\hline Total & 66 & $100.00 \%$ \\
\hline
\end{tabular}

\section{Discussion}

Our main objective was to evaluate the prescription of antibiotics in 187 patients admitted in December 2017 to the medical emergencies of Cocody UHC. Due to its retrospective nature, our study did not allow us to identify certain information that was incomplete or missing from certain files. These included some past history, place of residence and qualification of prescribers. The latter could influence the prescription of antibiotics. Nevertheless, our study allowed us to analyze epidemiological, clinical, paraclinical, drug and evolutionary data from antibiotic therapy administered in an emergency medical department.

\subsection{Socio-Demographic Data}

In our survey, the overall frequency of antibiotic prescribing was estimated at $58.62 \%(187 / 319)$. This frequency was higher than that estimated by ABA [8] in 2007 in the same medical emergency department (49\%). It could reflect a relative increase in antibiotic consumption in the said service due to the presence of many generic drugs at Cocody UHC. In our study, antibiotic prescribing involved male patients $(62.43 \%)$ with an average age of 47.50 years ( 46.31 years for men and 47.17 years for women) who worked in the informal sector $(n=87$; $46.52 \%)$. These results were comparable to those of a Moroccan study [12] in which 105 antibiotic prescriptions were recorded in 57 men (54.3\%) and 48 women patients (45.7\%) with an average age of 40 years.

\subsection{Clinical and Paraclinical Data}

In our study, fever $(\mathrm{n}=27 ; 14.44 \%)$ and consciousness disorders $(\mathrm{n}=23$; 
$12.30 \%)$ were the most frequently reported reasons for admission. Previous Ivorian studies [8] [9] [10] also highlighted fever as the main reason for consulting patients treated with antibiotics. Our reasons for admission, available in 121 files, were related to a lung disorders $(n=39 ; 32.23 \%)$. This was acute pulmonary disease $(n=25 ; 20.26 \%)$, acute bronchitis $(n=8 ; 20.51 \%)$, tuberculosis $(n=$ $5 ; 12.82 \%)$ and miliary tuberculosis $(n=1 ; 2.56 \%)$. These results could be explained by the prevalence of lung disease during the period of harmattan. In fact, the harmattan is a continental trade wind, dry, charged, most often, with dust that weakens the respiratory tract. It appears seasonally, usually between end of November and the beginning of January. Lung disease was also reported by $\mathrm{Pa}$ try et al. [11] in $23.5 \%$ of patients treated with antibiotics. Similarly, lower respiratory infections accounted for $25.7 \%$ of antibiotic prescriptions in a Moroccan study [12].

In our survey, antibiotic therapy was initiated on the basis of paraclinical (42.78\%), clinical (37.97\%) or clinical and paraclinical (19.25\%) arguments. This suggested probabilistic antibiotic therapy because no microbiological tests results were available in our files. These results were different from Elbouti et al. [13] who reported that $49.52 \%$ of patients treated with antibiotics were prescribed microbiological examinations. Futhermore, ABA [8], in 2003, noted an antibiotic therapy initiated on the basis of clinical (70\%) or clinical and paraclinical arguments (30\%).

In our work, paraclinical tests were performed on $85.56 \%(160 / 187)$ of patients treated with antibiotics with no significant difference (Chi $2=1.54$, ddl = $1, \mathrm{p}=0.21$ ). Thus, BFC showed hyperleukocytosis with neutrophilic and neutropenia in $43.75 \%$ and $7.50 \%$ of cases respectively. The contribution of BFC to the diagnosis of bacterial infection in emergencies is limited because this blood test does not allow for a reliable distinction between the bacterial origin and the infection. It provides guidance (neutrophilia or neutropenia in severe infections) which is especially useful when there is no specific clinical diagnosis [14] [15]. Apart from BFC, $97.70 \%$ of CRP requested in our study were positive. CRP is widely used in the diagnosis and therapeutic monitoring of infections because of its very high sensitivity and rapid evolution. However, its interest in emergency medicine is also very limited due to his lack of specificity [16] [17].

Furthermore, no procalcitonin assays and microbiological examinations results were found in our files. Procalcitonin is a relevant marker in the diagnostic and therapeutic approaches to bacterial infections in emergency department. Its serum level increases in cases of severe bacterial or parasitic infection with a sensitivity comparable or slightly lower than that of CRP but with a better specificity [14]. Procalcitonin can therefore be used to distinguish between cases that warrant antibiotic therapy and those that require prompt treatment.

\subsection{Therapeutic Data}

In our study, the beta-lactam family accounted for $70.57 \%$ of all antibiotic prescriptions. This percentage was comparable to that of SOLTANI [12] in Marra- 
kech, who had estimated beta-lactam prescription at $65.4 \%$. Of these beta-lactamines, the fixed association amoxicillin + clavulanic acid was the most prescribed $(n=113 ; 42.64 \%)$, particularly in acute lung disease $(n=25 ; 22.12 \%)$, early infectious complications of hemorrhagic stroke $(n=13 ; 11.50 \%)$ and severe sepsis ( $\mathrm{n}=8 ; 7.08 \%)$. Sogodo et al. [18] estimated in their study the first-line prescription of beta-lactam at $42.51 \%$.

In our survey, antibiotic therapy was given as monotherapy (199 prescription lines; $75.38 \%$ ) and in associations (66 prescription lines; 24.90\%). Our frequency of antibiotic monotherapy was similar to that of Goulet et al. [19]. It was justified because the vast majority of infections observed in medical emergency department are mostly community-based and therefore germs are generally sensitive to antibiotics frequently used in monotherapy. Under these circumstances, the use of antibiotic combinations should meet three objectives. The first objective is to increase the effectiveness of the treatment by increasing the bactericidal power through the synergistic effect of the combination. This is one of the objectives of antibiotic therapy for septic shock, acute endocarditis and neutropenic infections [19] [20]. The most interesting synergistic bactericidal activity is observed with the association of beta-lactam with aminosides or fluoroquinolones [19] [20]. The second objective of the association is to expand the antibacterial spectrum in the treatment of severe microbiologically undocumented infections (purulent meningitis, severe pneumonia) or potentially plurimicrobial infections (necrotizing cellulitis, intraabdominal infections) [19] [20]. The third objective is to prevent the foreseeable emergence of resistant mutants during the eradication of certain bacterial species by certain antibiotics (fluoroquinolones, rifampicin, fucidic acid in staphylococcals; fluoroquinolones, beta-alactamines in Pseudomonas aeruginosa infections).

In our study, the intravenous route was the most commonly used for antibiotic administration (84.41\%) with an average treatment duration of $3 \pm 1$ day. This preferential use of the intravenous route could be explained by the emergency situation that required the maximum bioavailability of the drug. Classically in mild infections, the duration of antibiotic therapy is 4 to 7 days [19] [20]. In our work, our short duration of antibiotic therapy could be explained by two factors. The first factor was the benign nature of some infections that did not require hospitalization. The second factor was related to the transfer of patients, usually within 24 hours to 72 hours, once their health stabilized.

In our work, antibiotic therapy was not relevant in $66.41 \%(176 / 265)$ of the prescription lines for indication with a non-compliant dosage in $29.43 \%$ (78/265) of the prescription lines. This misuse of antibiotics was worrying because it could have adverse health consequences for patients and promote the emergence of resistant bacterial mutants. Thus, in our study, the health status of $50.80 \%$ (95/187) of patients improved on antibiotic therapy and a significantly different favourable evolution (Chi deux $=67.09$, ddl $=1, \mathrm{p}=0.001$ ) was reported in case of relevant antibiotic therapy. However, symptoms had worsened in $6.95 \%(15 / 187)$ of the patients and 29 deaths $(15.51 \%)$, difficult to attribute to 
antibiotic therapy, were reported. These deaths underscored the importance of efficient diagnosis and rational antibiotic therapy in medical emergencies department at Cocody UHC.

\section{Conclusion}

Antibiotic therapy in medical emergencies at Cocody University Hospital Centre (UHC) was generally based on probabilistic reasoning. In addition, we found that more than half of antibiotic treatments were inappropriate. It is therefore important to take measures to avoid the emergence of resistant bacterial strains. This implies that the emergency physician should have a good knowledge of the rules of use of antibiotics and that he endeavours to comply with them. Furthermore, it would be useful to conduct a multicentre study in the emergency medical services of the Abidjan Health District in order to better assess the relevance and compliance of antibiotic therapy.

\section{Conflicts of Interest}

The authors declare no conflicts of interest regarding the publication of this paper.

\section{References}

[1] Mazliak, P. (2019) Antibiotics (Time Markers). http://www.universalis.fr/encyclopedie/antibiotiques-reperes-chronologiques

[2] Tremolieres, F., Cohen, R. and Schlemmer, B. (2006) Requiem for Antibiotics. Should We Fear the Disappearance of Antibiotics? Therapeutic Medicine, 12, 154-159.

[3] Moberg, C. and Dubos, R. (1996) A Harbinger of Microbial Resistance to Antibiotics. Microbial Drug Resistance, 2, 287-297. https://doi.org/10.1089/mdr.1996.2.287

[4] Fleming, A. (1945) Penicillin's Finder Assays Its Future. New York Times of June $26,21$.

[5] World Health Organisation (2004) Antimicrobial Resistance: Global Report on Surveillance. Geneva.

[6] Kostyanev, T., Bonten, M.J.M., O’Brien, S., Steel, H., Ross, S., François, B., et al. (2016) The Innovative Medicines Initiative's New Drugs for Bad Bugs Programme: European Public-Private Partnerships for the Development of New Strategies to Tackle Antibiotic Resistance. Journal of Antimicrobial Chemotherapy, 71, 290-295. https://doi.org/10.1093/jac/dkv339

[7] Société de PathologieInfectieuse de Langue Française (2002) How to Improve the Quality of Antibiotic Therapy in Healthcare Facilities. Med Mal Infect, 32, 320-328. http://www.infectiologie.com/UserFiles/File/medias/_documents/consensus/atb-02. pdf

[8] Aba, Y.T. (2003) Analysis of Antibiotic Therapy Practices in the Emergency Medical Departments of the Three C.H.U. of Abidjan. Thèse Med., UFR Sciences Médicales University of Cocody, Abidjan, 3599.

[9] Sow, M.S., Camara, A., Fortes Deguenonvo, L., Medila, M.A., Barry, M., Diallo, A.A.S., Cisse, M., Camara, L.M. and Ndoye, B. (2012) Evaluation of the Prescription of Antibiotics in the Lower Respiratorytract Infections in Adults at the University 
Hospital of Conakry in Guinea. Rev. CAMES-Série A, 13, 239-243.

[10] Avaoka, L.F. (1987) Study of Hospital Prescription of Antibiotics [PHD]. UFR Medical Sciences University of Abidjan, Abidjan, 853.

[11] Patry, I., Leroy, J., Hénon, T., Talon, D. and Hoen, B. (2008) Evaluation of Antibiotic Prescription in a French University Hospital. Médecine et Maladies Infectieuses, 38, 3378-3382. https://doi.org/10.1016/j.medmal.2008.03.009

[12] Soltani, L. (2014) Evaluation of Antibiotic Prescriptions in an Emergency Department of the CHU Mohamed VI in Marrakech. Thesis Med., Faculty of Medicine of Marrakech, Marrakech.

http://wd.fmpm.uca.ma/biblio/theses/annee-htm/art/2014/article20-14.pdf

[13] Elbouti, A., Rafai, M., Chouaib, N., Jidane, S., Belkouch, A. and Bakkali, H. (2016) Evaluation of Antibiotic Prescription in Emergency Rooms at the Mohamed V Military Training Hospital in Rabat. Pan African Medical Journal, 25, 162. https://doi.org/10.11604/pamj.2016.25.162.7080

[14] Malvy, D., Grand Bastien, B. and Cenn, I. (1992) Antibiotic Consumption at the University Hospital of Tours. Médecine et Maladies Infectieuses, 12, 1159-1165. https://doi.org/10.1016/S0399-077X(05)81431-3

[15] Wyllie, D.H., Bowler, I.C. and Peto, T.E. (2004) Relationship between Lymphopenia and Bacteraemia in UK Adults with Medical Emergencies. Journal of Clinical Pathology, 57, 950-995. https://doi.org/10.1136/jcp.2004.017335

[16] Badiaga, S. and Gerbeaux, P. (2006) Antibiotic Therapy in Emergency Departments, Development. Reanimation, 15, 514-522. https://doi.org/10.1016/j.reaurg.2006.10.005

[17] Wyllie, D.H., Bowler, I.C. and Peto, T.E. (2005) Bacteraemia Prediction in Emergency Medical Admissions: Role of C Reactive Protein. Journal of Clinical Pathology, 58, 352-356. https://doi.org/10.1136/jcp.2004.022293

[18] Sogodogo-Soumahoro, N. (2001) Prescription of Antibiotics in Public and Private Pediatric Hospitals. Thesis Med., UFR Medical Sciences, University of Cocody, Abidjan, 2816.

[19] Goulet, H., Daneluzzi, V., Dupont, C., Page, B., Heym, B. and Auvert, B. (2009) Assessment of the Quality of Antibiotic Prescriptions in the Emergency Department of a CHU in the Paris Region. Médecine et Maladies Infectieuses, 39, 48-54. https://doi.org/10.1016/j.medmal.2008.09.022

[20] Laupland, K.B., Church, D.L. and Gregson, B.D. (2005) Blood Cultures in Ambulatory Outpatients. BMC Infectious Diseases, 5, 35. https://doi.org/10.1186/1471-2334-5-35 